\title{
THE IMPACT OF FATIGUE ON LABOUR PRODUCTIVITY: CASE STUDY OF DAM CONSTRUCTION PROJECT IN QUEENSLAND
}

\author{
Conor O'Neill \\ Royal Australian Air Force and \\ Former Industry Affiliates Program Student, Griffith School of Engineering, Griffith \\ University, Queensland, AUSTRALIA \\ Email: conor.oneill@defence.gov.au \\ Kriengsak Panuwatwanich ${ }^{\dagger}$ \\ Griffith School of Engineering, \\ Griffith University, Gold Coast Campus, \\ Queensland, 4222, AUSTRALIA \\ +617-5552-7357, Email: k.panuwatwanich@griffith.edu.au
}

\begin{abstract}
The aim of the research presented in this paper was to conduct a study on the extent of the fatigue impact on the productivity of a construction crew in a dam construction project in Queensland, Australia. It was also aimed to examine economic implications associated with the affected productivity due to fatigue and to provide recommendations for improvement. To achieve the research aims, the Palm Psychomotor Vigilance Task (PVT) reaction tests were used to measure the reaction time of a sample of concrete crew members at different times during the day onsite over a one-week period. By measuring the reaction times of workers, the relevant levels of fatigue were determined. Productivity was measured using the Labour Utilisation Factor (LUF) by observing productive, supportive and non-productive times of the sampled crew onsite. The results from the tests showed that fatigue was present in sampled workers. The highest levels of fatigue were found to be due to high temperatures and physical exhaustion. The results showed that as fatigue increased among workers, the productivity dropped. It was found through a correlation analysis that fatigue had a negative association with the level of productivity. It was also found through productivity analysis that the average cost due to fatigue causing decreased production rates was $\$ 50,000$ per annum for a concrete crew consisting of 10 members. The main recommendations were to mix the work between difficult and simple work for crew members, scheduling to arrange this mix, and allowing short breaks while temperatures and humidity is high. Some other suggestions include the use of salt tablets to minimise fatigue caused by dehydration and an increase of shaded areas for worker breaks on the spillway.
\end{abstract}

Keywords: Australia, Construction, Fatigue, Labour, Productivity

\section{INTRODUCTION}

With the apparent rise in construction after the Global Financial Crisis, large construction companies are aiming to increase works. Project profits are affected by a wide range of factors that can and cannot be influenced by management. Worker fatigue is an issue that can greatly affect the productivity of a company. Therefore it is important for management to create mitigation and management plans that allow for the maximum productivity of its employees and work crews.

$\dagger^{\dagger}$ Corresponding author 
The contraction of global economy has led to an exponential decrease in projects especially in the construction industry. In Australia, these effects are also noticeable particularly within the context of this research - the state of Queensland, Australia. The Access Economics (2010) states that Queensland has felt the pinch of the economic strain with very little opportunities for large construction companies to obtain projects. There has been noticeably less construction of high rise and company development plans. Starting in 2010, Calligeros (2010) reported that Queensland is in the midst of a chronic housing production shortage, with up to 37000 jobs in the construction industry at risk. Queensland's housing industry has reached its lowest share of the national sector in two decades. New housing production has dropped 30\% since the middle of 2008 while overall construction has fallen by $8.5 \%$. For this reason, construction companies are required to be more competitive by offering best value to the clients. One way to achieve this is by completing projects within the shortest time possible.

When it is necessary to compress a schedule, the decision that the contractors make in selecting an acceleration technique depends on the duration and time until the project is to be completed. Several studies indicate that the most common way of increasing on-site labour force includes either to work longer hours, to add more labour, or to implement multiple shifts instead of a single shift (Noyce and Hanna 1998: Horner and Talhouni 1996). According to Hanna et al. (2008), one of the reasons shift work is preferred to overtime or overmanning is that the infrequencies from physical fatigue caused by overtime work and congestion problems associated with overmanning can be avoided. Worker fatigue affects employees and organisations around the world. Reduced production rates and social restrictions are just some of the consequences of poor fatigue management. Thus, fatigue is a problem for both employees and employers.

Fatigue also has an economic implication on productivity. Construction labour costs are generally known to be about 33-50\% of the total project budget (Hanna et al., 2008). According to Hanna et al. (2008), the profit margins of labour intensive constructions are typically $2-3 \%$ of the total project budget; therefore, understanding the effects of labour productivity is crucial. Through good management, labour costs have a possibility to decrease. An increase in productivity reduces labour cost resulting in lower project cost, thus making it of high importance to management (Hanna et al., 2008).

In this report, the study of the effect of overtime and working conditions of a large dam upgrade project within the city of Gold Coast, Australia is presented. This case study project was carried out by a special alliance of multiple organisations formed to manage and finance the project. The research presented in this paper was conducted by the first author of this paper as part of the Griffith University's Industry Affiliates Program (IAP) in conjunction with the main contractor (as the industry partner) responsible for the dam upgrade project. The bulk of the works on the dam upgrade project is the raising of the dam wall and the dam 
spillway. The industry partner company employs over 300 workers on the project, most of which form the main part of working and construction crews.

The aim of this research was to determine if fatigue had an effect on the productivity of the construction work. To achieve this, levels of fatigue and the productivity of a concrete crew were measured. An analysis was further conducted to estimate the economic impact of fatigue on the project. A mitigation and management plan was also developed based on the findings. This includes options which the industry partner company can implement in order to reduce fatigue on the project.

\section{THEORETICAL BACKGROUND}

\subsection{Fatigue Measurement and Analysis}

The analysis of fatigue in the workplace involves measuring the amount of fatigue that employees feel mentally and physically. Fatigue is a cumulative effect that occurs as sleep loss and deprivation build with the increase of the shift length and consecutive days. The current economic situation means that companies, not only in construction, are fighting to keep the business running. With a reduced amount of production, there is an increasing amount of competition between companies to secure a project and keep the project on time and successful for the possibility of future similar projects. Employees of large companies are therefore under increasing stress to work longer shifts in more consecutive days than ever before. The level of fatigue which employees incur accumulates over time; and therefore, the sleep debt from a week's work of long shifts can have a significant effect in latter stages of the working week.

Fatigue is often divided into physical and mental components. Physical fatigue refers to an acutely painful phenomenon which arises in overstressed muscles after exercise (Grandjean, 1979), and a symptom, which emerges in circumstances such as prolonged physical exertion without sufficient rest or sleep disturbances due to medication (Rockwell \& Burr, 1977). Mental fatigue reflects reduced psychological capacity and less willingness to act adequately due to earlier mental or physical effort, resulting in a reduced competence to maintain or initiate goal directed behaviour.

Fatigue is a multidimensional construct and can occur from a number of different reasons. Measuring fatigue can occur mentally and physically by the use of questionnaires and physical examinations. Objective measures such as reaction times or number of errors are good ways to assess how much fatigue a person may have (Akerstedt, 1990). Through using reaction tests, a clear indication can be seen if a person is suffering from fatigue. A reduced reaction time is a clear indicator that a person is suffering from fatigue and the reaction times can be taken throughout the day to show the reduced reaction times. 


\subsection{Economic Impact of Fatigue}

According to research by Amble (2007), it has been suggested that 38\% of workers experience fatigue related problems within the workforce. These problems range from low levels of energy to lethargy and inadequate sleep. The study looked at how fatigue affected the productive time of workers when they were at work. Ten percent of workers reported unproductive time and noted that fatigue reduced performance by mainly interfering with their concentration and increasing the time needed to accomplish tasks. Total loss of productive time was said to be 5.6 hours for workers who had fatigue, compared to 3 hours for their counterparts who did not have fatigue, an estimated cost of over (US\$)136 billion per year in productivity loss. The research shows that there can be economic advantages if these fatigue problems can be mitigated successfully. If measurements can be successfully taken for the physical and mental fatigue values which are present or persistent in the working crews, the ability to compare fatigue results with the production results will be possible.

\subsection{Measurement of Productivity}

The measurement of worker productivity can be found using many techniques which differ depending upon the job nature and the ability to calculate the amount of work achieved. The simplest form of measuring productivity is to divide the amount of work predicted by the actual amount done, which is easily computed in factory work or work where the repetition is high.

The actual work rates of construction crews are very hard to find as there are many factors that influence the production rates of workers. These factors are largely influenced by weather, logistics, and management. Weather plays a large part in influencing of productivity as rainfall means that no or very little work can be conducted safely on site, resulting in zero productivity for the day. Logistics and management also play vital roles in the productivity of construction crews, both having the ability to slow down the production process through poor management or delays, or speed up the production process through well designed plans.

The Labour Utilisation Factor (LUF) is used to measure the productivity of work crews in the construction industry (Oglesby et al., 1989). The theory uses a formula to describe how productive a group is working. The LUF uses a series of one minute observations during shifts throughout the day, giving the group a final percentage of productivity.

LUF (Labour Utilisation Factor) $\%=\frac{\text { Productive }+1 / 4 \text { Supportive }}{\text { Total number of workers }}$

Where:

Productive $=$ The total number of number of productive workers

Supportive $=$ The total number of supportive workers 
The LUF gives a result for the percentage of productivity which can then be compared with different stages of the day, week, and month. The Labour Utilisation Factor is discussed in depth in Oglesby et al. (1989).

\section{METHOD}

\subsection{Study Site and Participants}

The study was conducted at a large dam construction site located in the city of Gold Coast, Queensland, Australia. Data collection was carried out by the first author of this paper as part of Griffith University's Industry Affiliates Program (IAP) placement with the industry partner (the main contractor of the project). This IAP scheme provides final year students the opportunity to develop work-ready skills through the completion of an industry-based research project. The data collection for this study involved measuring reaction times and productivity rates of a concrete crew working in the project. The concrete crew was made up of experienced concreters and labourers; they played a major role in the construction of the project, which is made of $90 \%$ mass concrete work. All crews on site were employed to work a minimum of 10 hours per day, 5 days per week. However work on Saturday was a common occurrence on site, raising the weekly work total to more than 60 hours per week.

\subsection{Fatigue Assessment}

\subsubsection{Survey}

A questionnaire survey was used to measure the level of mental fatigue which was present in the group of concreters. The questions aimed at the level of fatigue which was felt by the group and at what times the crew felt the most fatigued. This was also aided by questions regarding the quality of sleep and health of the crew. The survey was the first initial testing which was performed on the concrete crew on the first day of the study week. The results of the survey were very important in order to form a fatigue mitigation plan for the industry partner.

\subsubsection{Personal Vigilance Task (PVT) Reaction Tests}

PVT reaction tests were used to measure the reaction time of a participant at different times during the day. The Palm PVT (see Figure 1) was used on site to determine the reaction times of participants in the research. Palm PVT testing equipment made the calculation of reaction times and other fatigue related characteristics easier. The equipment has the ability to be taken on site to measure the reaction times of concrete crews. The test has a 5-minute duration. To obtain a thorough understanding of the work involved and the exact feelings which the crew experienced, personal work within the concrete crew was undertaken. Work 
within this crew was done for one week, where Palm PVT testing could occur at the appropriate times. This enabled a real life perspective and gave a better understanding of how mitigation plans could be developed. The PVT testing of crew members was taken in the morning and afternoon only to reduce the amount of time which the members were absent from working. This main testing was conducted to see the pattern of fatigue among the crew members. In addition, another PVT testing over 7 different times throughout the day was further conducted with one of the crew members over a one-week period. This second test data was used to examine the relationship between fatigue and productivity levels.

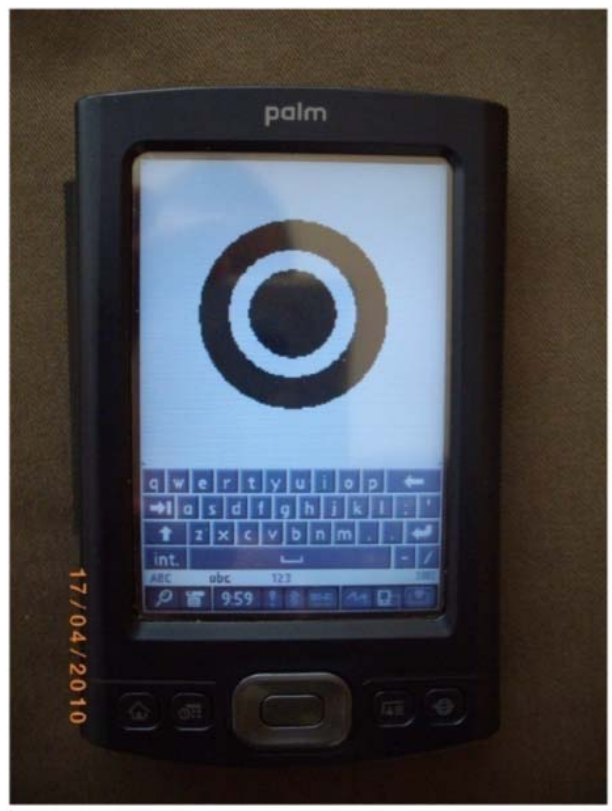

Figure 1: Palm PVT

\subsection{Productivity Measurement}

The Labour Utilisation Factor (LUF) was used during the project to identify the productivity levels of the concrete crew. Using Equation (1) shown in Section 2.3, a percentage level of productivity was calculated over 7 time points throughout the day. Productivity analysis is a major part of the research assignment. The data obtained from the productivity (LUF) results allowed for the comparison with fatigue and proved whether fatigue has an effect on the productivity of work. A concrete crew working on the project was used in the analysis of worker productivity. Criteria for determining key parameters for LUF calculation is presented in Table 1.

Table 1: Descriptions of LUF parameters

\begin{tabular}{|l|l|}
\hline Parameter & Description \\
\hline Productive & $\begin{array}{l}\text { Worker seen to be working efficiently; using concrete vibrator, } \\
\text { raking concrete, screeding, releasing concrete from kibble, testing } \\
\text { concrete (temperature etc.) }\end{array}$ \\
\hline
\end{tabular}




\begin{tabular}{|l|l|}
\hline Supportive & $\begin{array}{l}\text { Worker seen to be aiding in the efficiency of the concrete pour; } \\
\text { assisting in vibrating, assisting in positioning of kibble, general } \\
\text { assertion less that entirely efficient. }\end{array}$ \\
\hline Non-Productive & $\begin{array}{l}\text { Worker seen to be lacking in efficiency; sitting down, watching, } \\
\text { smoking, etc. }\end{array}$ \\
\hline
\end{tabular}

\section{ANALYSIS RESULTS AND DISCUSSION}

\subsection{Survey Results}

The results from the survey showed that the majority of the concrete team experienced mental or physical fatigue during a normal working week. The survey showed that 8 out of the 12 concreters experienced high levels of fatigue throughout a normal working week. The survey also showed that most workers in this crew were affected by mental fatigue for the past 6 months or more, indicating that the stresses of the job had accumulated over time. The results showed that heat, repetitive tasks, and lack of sleep were the main causes of fatigue in the crew. Over $65 \%$ of the crew were affected by heat whilst working, $55 \%$ affected by lack of sleep, and 58\% affected by repetitive tasks. It was also found that the energy level as reported by the crew was $55 \%$ on average and the feeling of fatigue on the day was moderate at $44 \%$ on average.

\subsection{PVT Reaction Test Results}

The PVT reaction test results presented in Table 2 show that there is a considerable increase in the reaction times from the start of the day to the end of the day. The average of the morning reaction times for the entire week was equal to 0.292 seconds, whereas the average for the afternoon was 0.352 seconds - a $21 \%$ increase. The increasing reaction time throughout the day shows that fatigue is present within the workforce.

Table 2: PVC Reaction Times

\begin{tabular}{|c|c|c|c|c|}
\hline \multirow[t]{2}{*}{ Day } & \multicolumn{2}{|c|}{$\begin{array}{l}\text { Mean Reaction Time } \\
\text { (seconds) }\end{array}$} & \multirow[t]{2}{*}{ Activity } & \multirow[t]{2}{*}{ Weather } \\
\hline & Morning & Afternoon & & \\
\hline Mon 12 April & 0.29 & 0.34 & 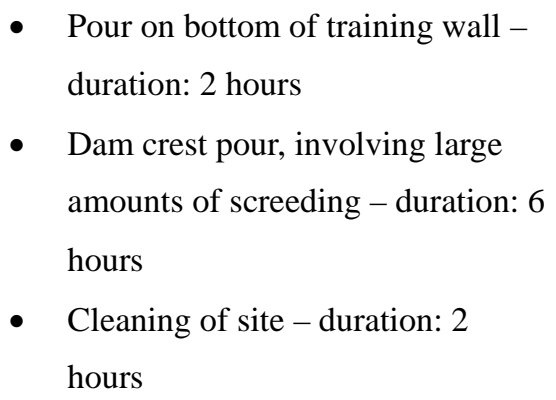 & Cloudy $22^{\circ} \mathrm{C}$ \\
\hline
\end{tabular}




\begin{tabular}{|l|l|l|l|l|}
\hline Tue 13 April & 0.30 & 0.32 & Cleaning and shovelling of site & Cloudy $24^{\circ} \mathrm{C}$ \\
\hline Wed 14 April & 0.27 & 0.33 & $\begin{array}{l}\text { Large pour on spillway - duration: } \\
\text { 6 hours } \\
\text { Second pour on spillway - } \\
\text { duration: 4 hours }\end{array}$ & Hot $30^{\circ} \mathrm{C}$ \\
\hline Thu 15 April & 0.26 & 0.38 & $\begin{array}{l}\text { Cleaning and preparation for pour } \\
\text { being conducted on Friday }\end{array}$ & Hot $30^{\circ} \mathrm{C}$ \\
\hline Fri 16 April & 0.34 & 0.39 & $\begin{array}{l}\text { Large pour on spillway - duration: } 9 \\
\text { hours }\end{array}$ & Hot $30^{\circ} \mathrm{C}$ \\
\hline
\end{tabular}

\subsection{Productivity Measurement Results}

Following the PVC reaction tests, the productivity of the concrete crews was measured and calculated to examine the relationship between fatigue and production rates. In addition, the productivity was further studied to identify the cost associated with the loss of productivity caused by fatigue. To measure productivity, the Labour Utilisation Factor (LUF) of the concrete crew was calculated for the duration of 2 weeks. Table 3 presents the weekly LUF values of the concrete crew that were averaged from the 2-week observation data for all the 7 observation times of a day. According to the table, the patterns of the LUF values across the five-day period indicate that productivity starts relatively low at the beginning of a day, peaks in the late morning, then drops off towards the end of the day. It is also apparent that the reduction of productivity after lunch time is highest on Friday.

Table 3: Mean LUF values for each of the 7 observation times of a day

\begin{tabular}{|c|c|c|c|c|c|c|}
\hline $\begin{array}{c}\text { Time } \\
\text { of day }\end{array}$ & Monday & Tuesday & Wednesday & Thursday & Friday & Day Avg. \\
\hline $6: 30$ & $76.3 \%$ & $77.5 \%$ & $92.5 \%$ & $83.8 \%$ & $76.3 \%$ & $81.3 \%$ \\
\hline $8: 00$ & $85.0 \%$ & $85.0 \%$ & $92.5 \%$ & $88.8 \%$ & $81.3 \%$ & $86.5 \%$ \\
\hline $10: 00$ & $88.8 \%$ & $88.8 \%$ & $92.5 \%$ & $88.8 \%$ & $85.0 \%$ & $88.8 \%$ \\
\hline $10: 30$ & $92.5 \%$ & $85.0 \%$ & $85.0 \%$ & $89.4 \%$ & $80.0 \%$ & $86.4 \%$ \\
\hline $13: 00$ & $83.3 \%$ & $81.3 \%$ & $92.5 \%$ & $88.8 \%$ & $78.8 \%$ & $84.9 \%$ \\
\hline $14: 00$ & $85.0 \%$ & $81.3 \%$ & $85.0 \%$ & $85.0 \%$ & $68.8 \%$ & $81.0 \%$ \\
\hline $16: 30$ & $70.2 \%$ & $73.8 \%$ & $77.5 \%$ & $76.3 \%$ & $48.8 \%$ & $69.3 \%$ \\
\hline Time Avg. & $83.0 \%$ & $81.8 \%$ & $88.2 \%$ & $85.8 \%$ & $74.1 \%$ & \\
\cline { 1 - 5 } & & & & &
\end{tabular}

\subsection{Relationship between Fatigue and Productivity}

To examine the relationship between fatigue levels (measured through PVT reaction times) and productivity (measured through LUF), an additional PVT test was conducted with 
one of the crew members (as a representative of the crew) everyday over one work week. The test was carried out at the same 7 time points throughout each day (as those used with the productivity measurement) so the PVT data could be used to correlate with the productivity data. The productivity data used was the daily mean LUF presented in Table 3. Correlation analysis was employed to determine the relationship between these two variables. Table 4 summarises the Pearson's correlation coefficients between the daily PVT reaction times and daily productivity (mean LUF) over the week. The table shows that there is a significant negative relationship between PVT reaction times and the LUF. This indicates that a higher level of fatigue (increasing PVT reaction times) is associated with lower productivity (i.e. lower level of LUF).

Table 4: Correlation results

\begin{tabular}{|l|l|l|}
\hline Day of week & $\begin{array}{l}\text { Pearson's correlation } \\
\text { coefficient }\end{array}$ & Sig. \\
\hline Monday & $-0.840^{*}$ & 0.018 \\
\hline Tuesday & $-0.815^{*}$ & 0.026 \\
\hline Wednesday & $-0.940^{* *}$ & 0.002 \\
\hline Thursday & -0.241 (n.s.) & 0.603 \\
\hline Friday & $-0.802^{*}$ & 0.030 \\
\hline
\end{tabular}

\subsection{Quantifying the Economic Impact of Fatigue}

The productivity data were further used to assess the economic impact of fatigue on the production. According to Burson (2004), the rule of thumb for calculating productivity using the Labour Utilisation Factor (LUF) for personnel in a firm is usually around 85\%, and the utilisation rate for total staff is $65 \%$ to make a profit. After consulting with the industry partner representatives (a project engineer, senior estimator and site engineer) a benchmark of $85 \%$ productivity has been set as a maximum productivity rate for the crew. Using this benchmark and the results of the productivity (LUF), the total cost to the industry partner company was calculated from the amount of time wasted due to non-productive work.

An average wage of $\$ 60 /$ hour is assumed for both concrete and formwork employees, with both spillway crews having an average of 10 people. The following figures were used to identify the cost in production losses incurred on the project.

- Average wage $=\$ 60 / \mathrm{hr}$

- $\quad$ Daily rate $=\$ 600$ per person

- Crew $=10$ members

- Crew Daily Total $=\$ 6,000$

- $\quad$ Crew Weekly Total $=\$ 30,000$ 
Based on the productivity data (LUF) obtained from the observed crew over two weeks, the average loss in productivity for each day is added together to form a weekly cost of fatigue. This cost has been calculated to be an average of $\$ 966$ or about $\$ 1,000$ per week. Over an entire year's production, the loss in production of this particular formwork crew equates to around $\$ 50,000$ in losses.

\section{FATIGUE MITIGATION PLANS}

Mitigation of fatigue is vital in order for the industry partner to increase productivity on any project. There are many different factors that influence fatigue; therefore, there is no single recommendation or theory that will eliminate fatigue from a workforce. However, there are strategies that can be implemented which will reduce the effects of worker fatigue. The mitigation plan is presented with respect to the main variables found to affect worker fatigue the most, as seen from the survey results presented in Section 4.1.

\subsection{Reducing Short-term Fatigue}

Supervisors and management play an important role in reducing fatigue. As heavy tasks cannot be performed continuously throughout the day, the scheduling of work is important to reduce the effects of fatigue. If a concrete or formwork supervisor knows that physically demanding work is going to be carried out during the day, it is important for them to schedule and plan to mix light work and heavy work. Muscles require energy not only to contract but also to resist movement. According to Oglesby et al. (1989) the time that this resistance can be sustained depends on the ratio between the required holding force and the maximum force that can be resisted. They further state that a tensed muscle can hold $15 \%$ of its maximum resistance indefinitely, $50 \%$ for 1 minute, but maximum force for only 6-7 seconds. This could be applied to concreters who were working on the studied project where large amounts of forces were exerted when positioning concrete kibble for pours, holding and moving vibrators to increase the workability of the concrete, and also screeding the concrete levels. A way to reduce the effects of fatigue whilst workers are undertaking these duties is to swap people into different duties at regular times during the day, mixing the heavy work with light work. Rohmert's Law clearly states that fatigue results when muscles are under load whether or not there is movement and also states that to prevent fatigue, tasks should be designed to avoid activities, such as holding heavy loads or pushing hard against non-moving objects. This can be directly associated with standing in wet concrete for extended periods of time and pushing against non-moving kibbles. Action should be taken by supervisors to ensure that crane operators and dogman on site position kibbles filled with wet concrete in correct and suitable positions to reduce the amount of movement conducted by concrete crew members. This will stop the pushing force exerted on the extremely heavy kibble by members of the concrete crew and reduce worker fatigue in the crew. 


\subsection{Long Term Fatigue Due to Overtime}

Overtime work is designed to increase the amount of time spent at work in order to speed up delivery dates of projects. The amount of overtime spent on the studied project was not overly excessive but even small amounts of overtime can add up over a long period of time. Ten-hour days, 5 times a week is the minimal hours worked by crews on the upgrade; however, many weeks were increased with the crews working weekends making the total time spent at work around 60 hours per week. The reduced productivity as the weekdays approach the weekend can clearly be seen in Section 4.3.

\subsection{Break Times}

Break times and amounts are important things for management to consider when organising daily schedule for labour workers on any construction site. According to Oglesby et al. (1989), worker productivity is reduced after breaks for a small period of time, depending on the amount of breaks taken and their time during the day. Increased short interval breaks can have a positive impact on the productivity of the entire work crews over the duration of a day. The current break times and lengths used by management of the studied project were:

- Smoking (cigarette break): 10.00am - 10.20am

- Lunch: 1.30pm - 2.00pm

It can be seen in Table 3 that after lunch has finished there is an observable reduced productivity which does not completely recover for the entire afternoon. One suggestion is to increase worker breaks to 3 times per day, with the following schedule:

- Smoking: 9.00am - 9.15am

- Break: 12.00pm - 12.15 pm

- Lunch: 2.00pm - 2.20pm

This theory could be applied in practice and the results could be calculated by the industry partner to identify whether this would have a positive effect on the production levels of the studied project.

\subsection{Heat}

Humans operate effectively in comfort zones where temperature ranges from $15-25^{\circ} \mathrm{C}$ under wide ranges of relative humidity. In this comfort zone, body and skin temperatures remain near normal since heat is dissipated by evaporative effects in respiration and through the skin without much sweating. According to Oglesby et al. (1989), at high temperatures, augmented by higher relative humidity, productivity declines.

The major cause of fatigue shown in the survey results in Section 4.1 was due to heat and exhaustion. Heat exhaustion arises from an excessive loss of salt and water. It is important 
that during high temperature days, water is kept in the body through constant rehydration. This could mean that workers be allowed small breaks every 10-15 minutes to enable them a drink of water and rest. Salt losses in the body lead to increased loss of water in urine, causing dehydration. This has been seen in past construction projects including the building of another dam, the Hoover Dam in the USA's southwest region. Heat stresses and salt deficiencies were brought to the attention of the Hoover Dam constructors when workers were collapsing under high temperature and humidity conditions. The high sunlight reflectivity of concrete and low shade made the heat conditions unbearable for most workers. To combat the problem, management ordered all workers to take salt tablets. This type of fatigue management could be employed by the industry partner, and advice about the benefits of increased salt intake in the work crew's diet could be explained to work crews by management. Clothing also makes a large difference on heat intensity. Worker uniforms could be revised to allow for more breathable material or clothing design. The long dark cotton pants work on site could be revised to a more breathable material.

\section{CONCLUDING REMARKS}

The objective of the research presented in this paper was to investigate the effect of fatigue on the construction productivity of a dam upgrade project in the city of Gold Coast, Australia. To investigate the effects of fatigue, the relationship between fatigue and productivity was analysed. The goal was to analyse the level of fatigue present on the project due to overtime and increased working hours and the current working conditions adopted by the main contractor. To investigate the relationship between fatigue and production, data was obtained on both the levels of fatigue which were present in the project and the productivity of the project. These two variables were determined by using the hand held Palm Psychomotor Vigilance Task (PVT) reaction time testing equipment and the Labour Utilisation Factor (LUF), respectively.

Using LUF to determine the productivity rates on the project meant that the productivity could be determined at any stage in the day. The results showed that as fatigue increased among workers, the productivity dropped. This was confirmed through a correlation analysis, which showed that fatigue had a negative association with the level of productivity. It was also found through productivity analysis that the average cost due to fatigue causing decreased production rates was $\$ 50,000$ per annum for a 10 -member concrete crew.

The results from the research also provided some evidence for the development of fatigue mitigation plans which could be adopted by the contractor company. The main recommendations were to mix the work between difficult and simple work for crew members, scheduling to arrange this mix, and allowing short breaks while temperatures and humidity is high. Some other suggestions include the use of salt tablets to minimise fatigue caused by dehydration and an increase of shaded areas for worker breaks on the spillway. 


\section{REFERENCES}

Access Economics (2010) The Pace of Housing Construction in Queensland: The Economic Implications. The Urban Development Research Institute, Queensland, Australia. http://www.udiaqld.com.au/Uploads/PDFs/Research\%20Papers/FINAL_The_Economic _Implications_March_2010.pdf.

Åkerstedt, T. (1990) Psychological and psycho-physiological effects of shift work. Scandinavian Journal of Work, Environment \& Health, 16, 67-73.

Amble, B. (2007) Fatigue Hits U.S. Productivity, Management-Issues: Health and Wellbeing, Work/Life Balance. http://www.management-issues.com/news/3899/fatigue-hits-us-productivity/

Calligeros, M. (2010) Queensland Construction Collapse: 37,000 at Risk, Brisbane Times, March,http://www.brisbanetimes.com.au/queensland/queenslandproperty/queensland-co nstruction-collapse-37000-at-risk-20100326-r1gf.html.

Grandjean, E. (1979). Fatigue in industry. British Journal of Industrial Medicine, 36, 175186.

Horner, R. M. W. and Talhouni, B. T. (1995) Effects of accelerated working, delays, and disruptions on labour productivity, Chartered Institute of Building, Ascot, Berkshire, U.K.

Hanna, A.S., Chang, C.K., Sullivan, K.T. and Lackney, J.A. (2008) "Impact of shift work on labor productivity for labor intensive contractor”, Journal of Construction Engineering and Management, 134, 197-204.

Noyce, D. A. and Hanna, A. S. (1998) Planned and unplanned schedule compression: The impact on labour, Construction Management and Economics, 16, 79-90.

Oglesby, C. H., Parker, H. W. and Howell, G. A. (1989) Productivity Improvement in Construction. McGraw-Hill, New York.

Rockwell, D.A. and Burr, B.D. (1977). The tired patient. The Journal of Family Practice, 5, 853-857. 